\title{
Diacronie
}

Studi di Storia Contemporanea

$N^{\circ} 28,4 \mid 2016$

La voce del silenzio

\section{El espionaje militar republicano durante la Guerra Civil Española}

\section{Hernán Rodríguez Velasco}

\section{Q OpenEdition \\ 1 Journals}

\section{Edición electrónica}

URL: http://journals.openedition.org/diacronie/4686

DOI: $10.4000 /$ diacronie.4686

ISSN: 2038-0925

\section{Editor}

Association culturelle Diacronie

Referencia electrónica

Hernán Rodríguez Velasco, «El espionaje militar republicano durante la Guerra Civil Española », Diacronie [En línea], № 28, 4 | 2016, documento 2, Publicado el 29 diciembre 2016, consultado el 21 diciembre 2020. URL : http://journals.openedition.org/diacronie/4686 ; DOI : https://doi.org/10.4000/ diacronie.4686 


\title{
Diacronie
}

N. 28 | 4|2016 La voce del silenzio: intelligence, spionaggio e conflitto nel XX secolo

2/

\section{El espionaje militar republicano durante la Guerra Civil Española}

\author{
Hernán RODRÍGUEZ VELASCO *
}

Al comenzar la Guerra Civil Española, el Ejército Popular de la República tuvo que crear unos servicios de inteligencia útiles para conocer las capacidades e intenciones de su enemigo. Manuel Estrada Manchón fue el oficial encargado de llevar a cabo esta tarea, creando negociados especializados. En este artículo se estudia no sólo el origen y la evolución de estos servicios, sino también su eficacia durante las batallas más importantes del conflicto. Con ello se pretende valorar la responsabilidad que la información tuvo en la derrota final de las fuerzas republicanas.

\section{Introducción}

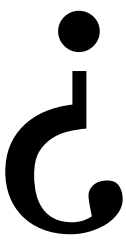

Por qué perdió la Guerra Civil Española el bando republicano? Muchos historiadores y estudiosos han intentado dar diversas explicaciones y respuestas a esta pregunta. Nuestra intención en este artículo es aportar un poco más de luz sobre el tema, tratando de determinar hasta qué punto los servicios de información fueron responsables de aquella derrota ${ }^{1}$.

Para ello hemos dividido el texto en dos partes: en la primera analizaremos los medios con los que contó el Ejército Popular desde el inicio de la contienda y cómo fueron evolucionando; mientras que la segunda mitad se centrará en conocer la eficacia de los servicios de información en los frentes.

Hemos acotado el término espionaje al trabajo desempeñado por los servicios dependientes de la Segunda Sección de Información del Estado Mayor del Ejército

${ }^{1}$ Un estudio más amplio de este tema en RODRÍGUEZ VELASCO, Hernán, Una derrota prevista. El espionaje republicano en la Guerra Civil española (1936-1939), Granada, Comares, 2012 
Popular, es decir, lo que se refiere exclusivamente a la llamada información en campaña, que se desarrolla durante las batallas.

\section{Creación y desarrollo de los servicios de información}

\subsection{Los Servicios de Información antes de 1936}

Cuando estalló la Guerra Civil Española, los Servicios de Información asociados al Ejército no tenían como prioridad informar sobre las capacidades o intenciones de ejércitos enemigos. En puertos y zonas costeras, así como en el protectorado marroquí se vigilaban movimientos sospechosos de barcos o aviones extranjeros, contrabando de armas o maniobras militares de otras naciones en territorio español ${ }^{2}$. Sin embargo, las mayores preocupaciones de los Servicios de Información comprendían las posibles infiltraciones que dentro del Ejército podía haber de "extremistas", "separatistas", “comunistas", a juzgar por los informes secretos que se extendieron entre 1932 y $1936^{3}$.

El Ejército español había permanecido neutral durante la Gran Guerra, lo que puede explicar su retraso en este sentido, a lo que se une la tradición de las fuerzas armadas de atajar manu militari los problemas internos. Por todo ello no existía un servicio que atendiese adecuadamente a la información en campaña, pero sí se había creado el Negociado de Información Comunista en el Ejército (NICE), afecto al Estado Mayor Central, que en 1933 pasó a constituir la Sección del Servicio Especial (SSE)4 La misión principal de esta Sección era la de era alertar al Gobierno sobre posibles complots internos; labor que compartía con otras fuerzas y cuerpos de seguridad del Estado como la Dirección General de Seguridad, el Cuerpo de Vigilancia o la Guardia Civil.

Pero... ¿̇qué pasaría si España entraba en guerra? Durante las dos primeras décadas del siglo XX el Estado Mayor Central había publicado algunos manuales basados en la experiencia de la Guerra del Rif donde se definían por vez primera algunos preceptos básicos sobre la información en tiempo de guerra, así como la necesidad de formar un «Servicio especial de información»5. Sin embargo, no sería hasta los años treinta

\footnotetext{
2 Archivo General Militar de Ávila (AGMAV), A.20, L.1, C.2, D.1.

3 AGMAV, A.2, L.1, 2.1, 2.2.

4 HEIBERG, Morten, ROS AGUDO, Manuel, La trama oculta de la Guerra Civil. Los servicios secretos de Franco, 1936-1945, Barcelona, Crítica, 2006, pp. 2-7.

5 ESTADO MAYOR CENTRAL DEL EJÉRCITO, Enseñanzas de la Campaña del Rif en 1909, Madrid, Talleres del Depósito de la Guerra, 1911; UNGRÍA JIMÉNEZ, José, Estudio preparatorio de un ejercicio táctico de gran unidad sobre el plano, Madrid, Talleres del Depósito Geográfico e Histórico del Ejército, 1929.
} 
cuando aparecieron los primeros textos que profundizaban propiamente en el tema ${ }^{6}$. En uno de ellos, su autor, Julio Garrido, denunciaba sin tapujos: «Nos falta en España un cuerpo de doctrina en que se recopile y codifique cuanto se refiere a este importantísimo servicio. Algún día habrá que prestar a esta cuestión el interés que exige» 7 .

Apenas cuatro años después se redactó el primer Reglamento para el Servicio de Información en Campaña ${ }^{8}$. Este libro no sólo cubrió una necesidad sino que además serviría como base para ambos bandos durante la Guerra Civil. Antes de su inicio, sin embargo, pocos lo habían leído y, en palabras de Manuel Estrada, futuro jefe de los servicios de información republicanos, «[...] entre los militares que desde el principio nos pusimos al lado de la República, apenas si había dos o tres que lo conocieran»9. Había que partir de cero. Y no sólo en el tema de la información y el espionaje.

\subsection{Origen y organización de la Segunda Sección (julio 1936-julio1937)}

Para detener la rebelión de una parte de las fuerzas armadas, el Ejército fue disuelto por decreto, lo que paradójicamente provocó el vacío de autoridad en las tropas bajo orden gubernamental. Este hecho fue seguido del reparto de armas entre las milicias ciudadanas, lo que ayudó aún más a socavar al Ejército, que conservaba su estructura y forma, pero cuyas funciones quedaban suplantadas.

En esta situación, el Estado Mayor Central mantuvo sus competencias a pesar de que su radio de acción se limitaba a la zona central. Una de sus partes, la Segunda Sección, es decir, la Sección de Información del Estado Mayor del Ministerio de la Guerra, hizo las veces de "buzón central" a donde llegaban informaciones de todo el territorio. Su funcionamiento durante esos primeros meses se llevaba a cabo «con notoria deficiencia» ${ }^{10}$, debido al descontrol ya mencionado, donde los militares habían sido suplantados por civiles; y porque los rebeldes saboteaban y descifraban los telegramas enemigos ${ }^{11}$.

\footnotetext{
${ }^{6}$ GARRIDO RAMOS, Julio, La información en la Guerra. Misión de la 2. ${ }^{a}$ Sección de un E.M. en campaña y actuación de todas las armas, Madrid, Agencia Española de Librería, 1931; MEDINA SANTAMARÍA, José, Servicio de Información en Campaña (Síntesis de su organización y funcionamiento), Toledo, Imp. Rodríguez y C. ${ }^{\mathrm{a}}, 1933$.

7 GARRIDO RAMOS, José, op.cit., p. 175.

8 MINISTERIO DE LA GUERRA, Reglamento para el Servicio de Información en Campaña, Madrid, Imprenta y talleres del Ministerio de la Guerra, 1935.

9 Archivo Histórico del Partido Comunista de España (AHPCE), Fondo: Documentos militares de la Guerra Civil. Estado Mayor del Ejército soviético. Rollo 6, p. 323.

${ }^{10}$ Archivo de la Fundación Pablo Iglesias (AFPI), AFLC-197-31, ff. 1, 2.

${ }^{11}$ AGMAV, A. 54, L. 479, C. 1, D. 1, f. 33.
} 
Desde un primer momento, el comandante de Estado Mayor Manuel Estrada Manchón se puso al frente de dicha Sección, monopolizando prácticamente el cargo durante todo el conflicto ${ }^{12}$.

Como ocurriera con la estructura general del Ejército Popular de la República, la Segunda Sección intentó reorganizarse inmediatamente con el fin de prestar cuanto antes un servicio eficaz, de ahí que ya el 12 de agosto de 1936 se redactaran las Normas para la Organización y funcionamiento del Servicio de Información ${ }^{13}$. Esto era la teoría, porque la práctica, distaba mucho de satisfacer los deseos del mando: en toda región alejada del frente central apenas se acataban las órdenes dictadas desde el Ministerio de la Guerra. Las noticias sobre los frentes que llegaban a Madrid provenían generalmente de civiles y/o milicianos, salvo del frente aragonés, en donde se montó el primer servicio de información a base de agentes improvisados, mitad espías, mitad guerrilleros, que actuaban también al margen del Ministerio ${ }^{14}$.

Tan sólo las columnas que el Gobierno envió desde Madrid a luchar contra el avance rebelde hacia la capital, y que eran dirigidas por militares profesionales, informaban excepcionalmente al Estado Mayor, constituyendo incluso los primeros boletines de información asociados a una Gran Unidad, en este caso, el Ejército de Centro.

A pesar de ello, «nadie sabía por dónde andaban los "fachas"» ni por dónde pensaban atacar Madrid ${ }^{15}$. De tal forma que, cuando Francisco Largo Caballero, líder socialista, fue nombrado Presidente del Gobierno y Ministro de la Guerra el 4 de septiembre de 1936, lo primero que intentó hacer fue reconstruir el Ejército y reestructurar íntegramente el Estado Mayor, para mejorar su eficacia, Sección de Información incluida. Ésta se mantuvo como Segunda Sección en diversos decretos ${ }^{16}$, pero llegó a instituirse una heterodoxa Sexta Sección denominada Servicio Especial, dedicada a asuntos casi policiales y del espionaje.

\footnotetext{
12 Una biografía del personaje en RODRÍGUEZ VELASCO, Hernán, «Manuel Estrada Manchón. Coronel», in GARCİA FERNÁNDEZ, Javier (coord.), 25 Militares de la República, Madrid, Ministerio de Defensa, 2011.

13 AGMAV, C.227, Cp. 6, D.4.

14 RUFAT, Ramón, Espions de la République. Mémoires d'un agent secret pendant la guerre d'Espagne, Paris, Éditions Allia, 1990, pp. 20 et seq.

${ }_{15}$ AHPCE, Fondo tesis, manuscritos y memorias, Manuscritos 38/3.

${ }_{16}$ Diario Oficial del Ministerio de la Guerra, 176, 5 de septiembre de 1936, pp. 262-263; Diario Oficial del Ministerio de la Guerra, 214, 20 de octubre de 1936, p. 134.
} 


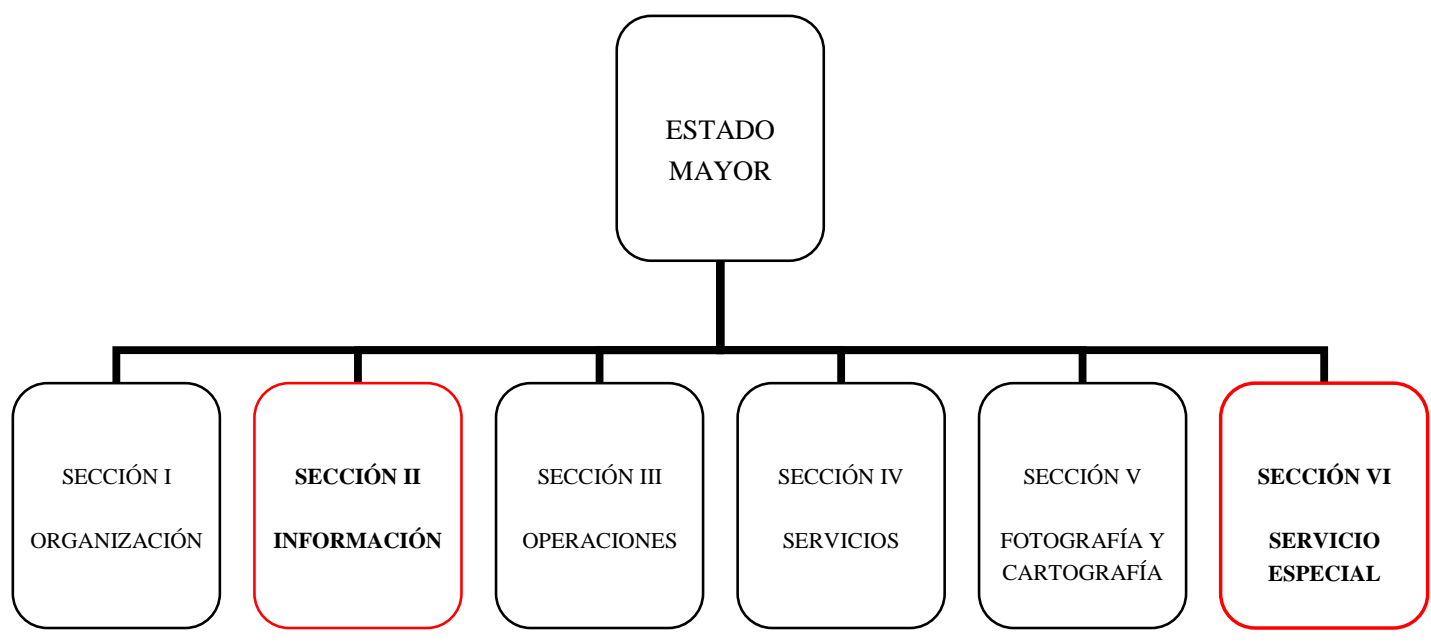

Tab. 1. Reorganización del Estado Mayor del Ministerio (2o octubre 1936)

A pesar de ello, las informaciones que llegaban al Ministerio seguían siendo remitidas mayoritariamente por civiles, que usaban la delación y el chivatazo para ejercer el contraespionaje; mientras que agentes especializados y/o guerrilleros nocturnos llevaban a cabo un trabajo aún muy rudimentario ${ }^{17}$.

Por su parte, las Grandes Unidades del Ejército Popular empezaron a desarrollar boletines de información de manera más "profesional”, como el citado caso del Ejército de Centro, pero también la Consejería de Defensa de la Generalitat, el Ejército del Norte y hasta las columnas andaluzas que se resistían a cualquier cambio.

Tras la batalla de Madrid, Largo Caballero decidió reorganizar de nuevo su Estado Mayor el 27 de noviembre con el fin de perfilar mejor sus funciones y órganos. La Segunda Sección aumentó entonces sus competencias dividiéndose en dos negociados: Servicio de Información General, encargado de las funciones básicas y el Servicio de Información Especial, que asumía las misiones de espionaje y contraespionaje de la efímera Sexta Sección ${ }^{18}$.

Este cambio no era suficiente pues la Segunda Sección contaba con unos cuadros inexpertos. Durante la primavera de 1937 proliferaron las disposiciones para inculcar en las Grandes Unidades el buen funcionamiento de los servicios de información aunque sin éxito. Según Estrada, la mejora del servicio se había ido forjando «en la experiencia, más que en los textos reglamentarios o de divulgación»19. Ciertamente, la práctica diaria había ido moldeando los servicios de información y los soldados, poco

17 RUFAT, Ramón, op.cit.; GUARNER, Vicente, Cataluña en la guerra de España, Madrid, G. del Toro, 1975, p. 178.

${ }_{18}$ Diario Oficial del Ministerio de la Guerra, 250, 30 de noviembre 1936, pp. 389-390.

${ }^{19}$ AHPCE, Fondo: Documentos militares de la Guerra Civil. Estado Mayor del Ejército soviético. Rollo 6, p. 323. 
cualificados militarmente, se habían ido acostumbrando a reglamentos y fórmulas que debían servir para mejorar los servicios de información y espionaje.

La marcha de las hostilidades imprimía una mayor responsabilidad al servicio, de tal manera que el 4 de mayo la Segunda Sección se reestructuraba nuevamente, para contar con otro negociado más, desdoblado de uno ${ }^{20}$.

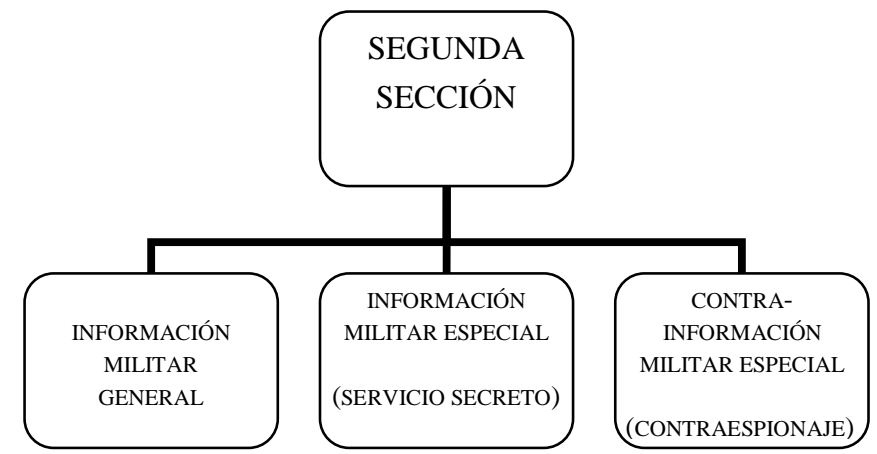

Tab. 2. Reorganización de la Segunda Sección del Estado Mayor del Ministerio (4 mayo 1937)

La Sección fue ampliando sus competencias conforme la complejidad de la guerra iba demandándole servicios más específicos, pero no sería hasta el mes de julio cuando ésta se reformaría completamente.

\subsection{Evolución y desarrollo (julio 1937-fin de la contienda)}

Manuel Estrada, que había pasado por diferentes puestos de mando durante el primer año de contienda, se hizo cargo definitivamente de la Sección de Información del Estado Mayor del Ejército de Tierra a mediados de julio y se dedicó a elaborar un proyecto para renovar la estructura del mismo y tratar de mejorar su funcionamiento. Estrada diseñó una sección con competencias y responsabilidades ampliadas, con la que pretendía transformar la Segunda Sección del Estado Mayor del Ejército de Tierra en el Servicio de Inteligencia Militar del Ministerio de Defensa ${ }^{21}$. Esto no gustó ni a Indalecio Prieto, recién nombrado Ministro de Defensa, quien pensaba que «sólo podía realizarse de él la parte que consentían los actuales derechos y atribuciones del Jefe del Servicio de Información» ${ }^{22}$, ni al coronel Vicente Rojo, Jefe del Estado Mayor Central, que rechazó el plan, por considerar que extralimitaba los poderes de Estrada, lo cual provocó la enemistad entre ambos militares.

${ }^{20}$ Centro Documental de la Memoria Histórica (CDMH), INCORPORADOS, 675, Cp. 6.

${ }^{21}$ Archivo Histórico Nacional (AHN), Archivo General Rojo, Caja 7/11.

$22 \mathrm{CDMH}$, Incorporados, 675, Cp. 21. 
Lo cierto es que la República se encontraba entonces en un momento muy delicado ya que el frente Norte estaba a punto de caer. La capacidad defensiva de los leales se iba deteriorando al tiempo que Franco llevaba la iniciativa. La información era una baza que, bien utilizada, podía ofrecer a la República unos réditos que era incapaz de obtener a través de la armas. Por ello, Estrada quería que la información jugara un papel central y decisivo. Se trataba de profesionalizar el servicio de una manera radical.

Para ello redactó el Reglamento para la organización y funcionamiento del Servicio de Inteligencia Militar del Ministerio de Defensa ${ }^{23}$. En dicho documento se reconocía la autonomía del propio Estrada para elegir a su propio personal y, lo más novedoso y revolucionario era la creación de unas secciones específicas que, tras varias denominaciones, finalmente quedaron así: Servicio de Información General de Frentes (SIGF); Sección de Información Especial Periférica (SIEP); la Sección de Servicio Secreto Estratégico se cambió por el Servicio de Información Especial Estratégico (SIEE); y el Servicio de Información Técnica (SIT).

El SIGF debía coordinar y sintetizar todos los boletines y partes que llegaban desde la Grandes Unidades (Ejércitos, Cuerpos de Ejército, Divisiones y Brigadas) para después elaborar los Boletines de Información para el Estado Mayor Central ${ }^{24}$.

El SIEP servía para informar sobre la retaguardia inmediata del enemigo a partir de las primeras líneas y por medio de agentes ${ }^{25}$. Para convertirse en espía había que demostrar «conocimientos militares, la técnica del trabajo clandestino y el sentido de la vigilancia» ${ }^{26}$. Jóvenes voluntarios sin preparación debían realizar un curso de diez días para llegar a ser agentes residenciales, viajantes o reservados. Los primeros vivían permanentemente en territorio enemigo; los viajantes cruzaban las líneas para llevar a cabo misiones de un par de días y los reservados se utilizaban sobre determinados sectores para recabar una mayor información.

A veces estos agentes eran confundidos con guerrilleros, por lo cual Estrada creó otro negociado en octubre de 1937, llamado Servicio de Información de Acción Militar (SIAM), con el fin de «informar sobre la retaguardia enemiga, realizar en ella acciones de sabotaje y provocar y preparar, coadyuvando a él en su debido tiempo, el

${ }^{23} \mathrm{CDMH}$, Incorporados, 675, Cp. 9, ff. 28-31.

24 AHN, Archivo General Rojo, Caja 7/11

${ }_{25} \mathrm{CDMH}$, Incorporados, 675, Cp. 12, f. 24 y Cp. 21

${ }^{26}$ AHN, Archivo General Rojo, Caja 7/11 
levantamiento en masa de la zona rebelde» ${ }^{27}$, aunque realmente no informaron mucho y más bien se dedicaron a hostigar al enemigo ${ }^{28}$.

Sin embargo, no todos los mandos del Ejército estaban de acuerdo con el uso de estos agentes. Muchos oficiales republicanos recelaban de unos soldados que sólo rendían cuentas a su negociado. Donde más se desarrolló esta sección fue en los frentes meridional y oriental, donde los frentes seguían siendo muy porosos. Sin embargo, de su utilidad se puede decir que el SIEP, aunque recogió información muy válida para adivinar las capacidades y posibilidades del enemigo, no llegó a conocer sus intenciones.

El SIEE tenía como cometido conocer «la situación de la zona de retaguardia profunda del enemigo y extranjero ${ }^{29}$. Las redes de agentes en el extranjero que habían operado hasta el momento, especialmente en Francia y en Marruecos, no habían sabido coordinarse con los propósitos del Ejército Popular. Además, la mayoría de agentes trabajaban para otros servicios parecidos en el extranjero por lo que su desarrollo no cuajó en absoluto.

Por su parte, el SIT se utilizó para escuchar y captar mensajes enemigos, así como para cifrar y descifrar despachos y formar claves útiles para el Ejército3o. La ayuda soviética fue fundamental para desarrollar este servicio, cuya eficacia llegó demasiado tarde. Del mismo modo, se creó otro servicio para analizar la documentación enemiga, el Servicio de Examen de Documentos (SIED) ${ }^{31}$, que debía leer la correspondencia enemiga, analizar la prensa y cualquier tipo de documentación, así como escuchar los partes de radio32. Se trataba de utilizar dicha información, no sólo de forma defensiva, sino que podía explotarse propagandísticamente. Por ello, en junio de 1938, el SIED fue sustituido por el SIP o Servicio de Información de Propaganda. El SIED también aportó pingües beneficios, entre otras cosas porque, aunque parezca mentira, en otoño de 1937, no había ningún encargado capaz de leer y traducir del alemán y del italiano. Por otro lado, la información recibida llegaba a cuenta gotas y con retraso ${ }^{33}$.

Por último, debemos constatar la creación del famoso SIM o Servicio de Investigación Militar el 29 de agosto de 1937. Con él se absorbían los negociados de

\footnotetext{
27 CDMH, Incorporados, 675, Cp. 12, f. 25.

28 Un estudio del SIAM en BLASCO, Domingo, CABRERA, Francisco, El Frente Invisible. Guerrilleros republicanos 1936-1939. De los niños de la noche al XIV Cuerpo, Guadalajara, Silente, 2013.

29 CDMH, Incorporados, 675, Cp. 3, f. 41. (s/f).

$3^{\circ} \mathrm{CDMH}$, Incorporados, 675, Cp. 9, f. 30.

${ }^{31} \mathrm{CDMH}$, Incorporados, 675, Cp. 11.

${ }^{2} \mathrm{CDMH}$, Incorporados, 730, Cps. 6.2, 6.4., 6.6, 6.8, 6.9, 7.1., 7.2, 743.

$33 \mathrm{CDMH}$, Incorporados, 721, Cp. 4, 743.
} 
espionaje y al contraespionaje ${ }^{34}$. Aunque concebido en su inicio como el servicio de contraespionaje militar, poco después sus competencias fueron más allá, lo que dejó de lado sus funciones primigenias relacionadas estrictamente con la información militar35. Desde ese punto de vista, el SIM nunca llevó a cabo un servicio eficaz en los frentes.

Durante un año entero, entre julio de 1937 y julio de 1938, el plan de Estrada se desarrolló sin sanción oficial. De facto, Estrada tenía bajo su mando a las ya conocidas secciones y contaba además con la colaboración de los servicios de información de Marina, Aviación, la Defensa Especial contra Aeronaves y la Artillería. Sin embargo, desde el verano de 1937 nadie había aprobado el proyecto, por lo que Estrada decidió mostrárselo a Juan Negrín, nuevo Ministro de Defensa, para que le diera su visto bueno en julio de 1938. De nuevo se pedía centralizar todas las secciones y convertir el Servicio del Ejército de Tierra en la Segunda Sección del EMC.

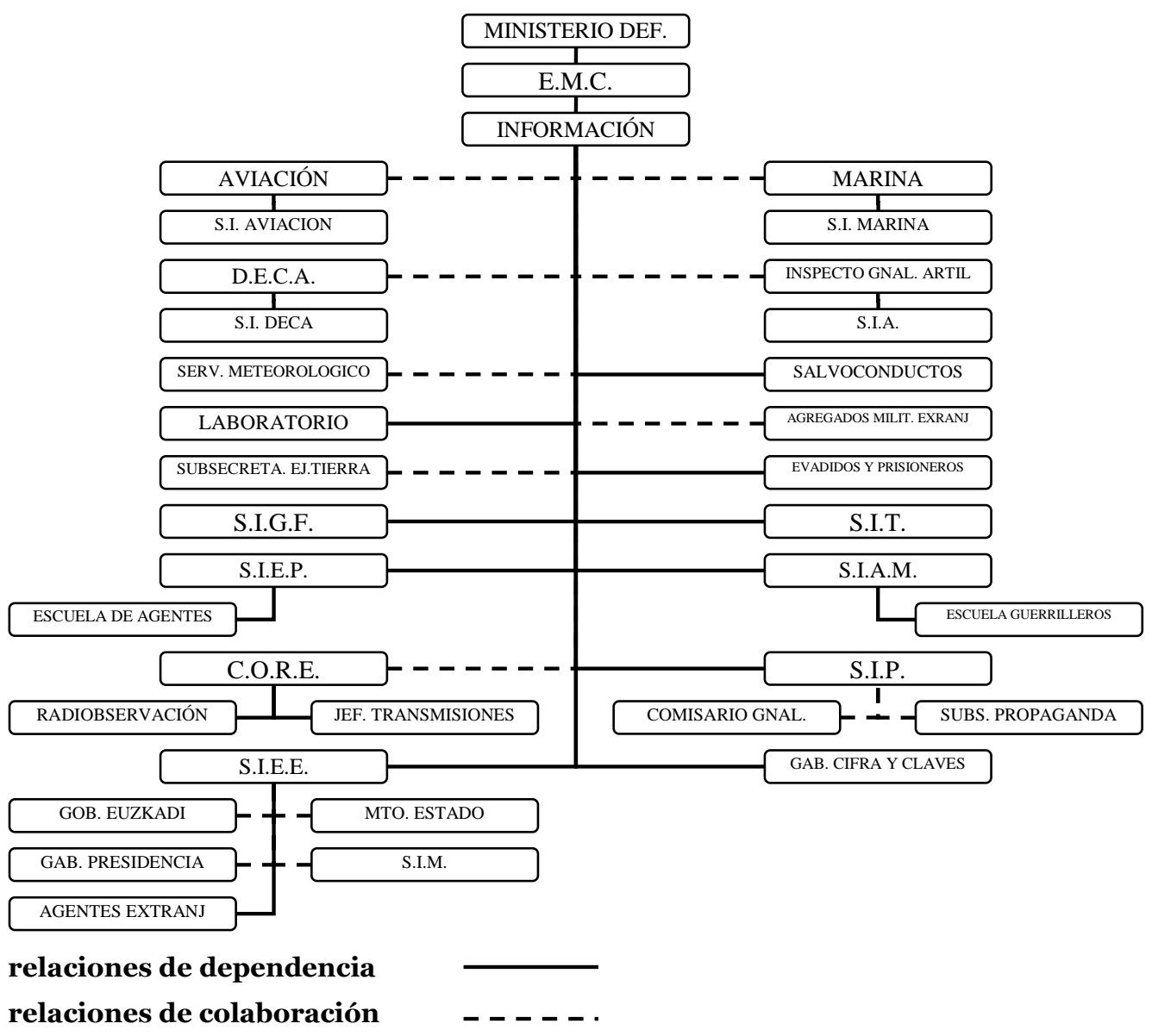

Tab. 3 Organización del Servicio de Inteligencia Militar del

Ministerio de la Defensa Nacional (Noviembre 1937-Agosto 1938) ${ }^{36}$

34 AHN, Archivo General Rojo, 7/11 y CDMH, INCORPORADOS, 675, Cp. 7.

35 RODRÍGUEZ VELASCO, Hernán, «Una historia del SIM: antecedentes, origen, estructura y reorganizaciones del contraespionaje republicano», in Ayer, 81, 1/2011, pp. 207-239.

${ }^{36}$ AHN, Archivo General Rojo, Caja 7/9. 
Sin embargo, una vez más, Vicente Rojo se opuso al proyecto pues entendía que el Servicio de Inteligencia Militar se convertiría así en una «entidad autónoma» del EMC. Lo curioso es que, a pesar de no aprobarse, el plan de Estrada siguió desarrollándose fuera de la legalidad. Demasiadas trabas para un proyecto ambicioso que sólo pretendía convertir una información deficiente y amateur en una sección más eficaz y profesional.

A pesar de ello, algo debió hacer bien Estrada cuando en diciembre de 1938, cuando ya estaba casi todo perdido, Juan Negrín y el propio Vicente Rojo reconocían que «el Servicio de Información ha patentizado de una manera notable la eficacia de su trabajo» y por ello le felicitaban a él y a todos sus subordinados por «haber logrado, no obstante la penuria de medios y recursos de todas clases, y la falta de auxiliares técnicos, tan indispensables en el Servicio, que se monte un Servicio de Información del que puede estar orgulloso el Ejército Popular y satisfechos los Mandos del mismo que explotan su trabajo» 37 .

Ciertamente, los servicios de información habían crecido y hasta asumido un papel importantísimo durante el conflicto. Llegados a este punto, la pregunta que debemos hacernos es pertinente: ¿funcionaron bien en la práctica? Para ello debemos analizar su uso y eficacia en los frentes de batalla.

\section{La información en las batallas}

\subsection{Mala información pero buenos resultados (noviembre 1936-marzo 1937)}

Cuando se inició la guerra, la descoordinación entre los frentes y la falta de unidad dentro de los partidarios de la República facilitaron el avance enemigo, que a finales de octubre se presentó a las puertas de Madrid sin encontrar apenas resistencia.

El 6 de noviembre el Gobierno abandonó la capital y se formó allí una Junta de Defensa encargada de defender la ciudad, con el general Miaja y el teniente coronel Rojo al mando. La información esperaba un ataque por el sur, «especialmente Cerro Rojo y el Campamento», por las posiciones «de Boadilla del Monte» ${ }^{8}$. Sin embargo, el 7 de noviembre en un golpe de suerte, se halló en la ropa de un cadáver enemigo el plan contra Madrid que desvelaba el lugar exacto por donde se iba a realizar el ataque ${ }^{39}$. Sería por el Noroeste, por lo que los defensores de la ciudad tuvieron que rectificar sus

37 CDMH, Incorporados, 736, Cp. 22, Exp. 4.

38 AGMAV, A. 57, L. 614, C. 1, D. 1, f. 14; AGMAV, A. 97, L. 953, C. 8, D. 1.

39 ROJO, Vicente, Así fue la defensa de Madrid, Madrid, Era, 1967, pp. 63-65. 
posiciones. Así, cuando se produjo finalmente el golpe el día 8, la penetración por la Casa de Campo y Ciudad Universitaria se detuvo en dicha zona y el enemigo no pudo avanzar mucho más. El ataque se había estancado y el alto el fuego se produjo el día 23. Madrid se había salvado de momento, pero seguía considerándose el objetivo estratégico fundamental.

Seis días después del alto el fuego, Franco y los suyos decidieron avanzar hacia el norte para cortar la carretera de La Coruña, algo que la información republicana no llegó a interpretar correctamente, ya que pensaba en un ataque enemigo por la zona del Jarama $^{40}$. En esta ocasión, las fuerzas republicanas resistieron nuevamente el envite.

Un segundo ataque se llevó hacia el oeste el día 14 de diciembre, pero de nuevo las fuerzas republicanas no advirtieron el peligro ${ }^{41}$, aunque el ataque no prosperó. Sin embargo, el 1 de enero el enemigo planteó una nueva acometida para dominar el paso por la carretera y ferrocarril de La Coruña. Una vez más, las fuerzas republicanas no vieron venir el golpe ${ }^{42}$. Esta vez las tropas del general Varela arrollaron las primeras defensas republicanas, aunque poco a poco la ofensiva fue deteniéndose conforme el teniente coronel Vicente Rojo acumulaba más unidades leales de refresco en la zona.

Algo similar ocurría en Málaga. La capital andaluza respiró tranquila hasta finales de noviembre cuando el general rebelde Queipo de Llano decidió avanzar hacia ella. Voluntarios italianos agrupados en tres columnas debían conquistar aquel sector. A comienzos de diciembre, aparte de los típicos rumores que circulaban por la ciudad, el cónsul de Gibraltar aseguró que «el ataque a Málaga se efectuará atacando por distintos frentes. El de Estepona queda excluido, pues la intención de los rebeldes es aislar este pueblo y una vez cercada Málaga caer sobre él»43. Málaga comenzó a suplicar ayuda a Madrid pero el enemigo no atacó entonces. Hasta mediados de enero no comenzarían las hostilidades. La información manejada por el mando republicano antes de la ocupación de Málaga era bastante fiable y veraz, aunque se contaba con una información limitada sobre los medios y efectivos del enemigo y algunos informes inflaron las cifras para justificar las peticiones de ayuda al Ministerio44. La ayuda llegó pero no fue suficiente porque en ese momento la República mantenía dos frentes abiertos, cuando sólo era capaz de atender el que tenía más cerca de la capital.

Málaga acabaría sucumbiendo el 8 de febrero y un mes después el enemigo lo intentaría en Pozoblanco (Córdoba), pero esta vez los servicios de información

40 AGMAV, A. 57, L. 614, C. 1, D. 1, ff. $18,32$.

${ }^{41}$ AGMAV, A. 97, L. 968, C. 12, D. 2, f. 23.

42 AGMAV, A. 97, L. 968, C. 12, D. 3, ff. 1, 5 .

${ }_{43} \mathrm{CDMH}$, Incorporados, 696, Cp. 9.

$44 \mathrm{CDMH}$, Incorporados, 711, Cp. 1. 
agudizaron sus sentidos y en la última semana de febrero denunciaron el propósito de los rebeldes de realizar un ataque en la zona Peñarroya-Belmez-Baeza-Luque-Priego 45. De esta forma, cuando la ofensiva comenzó el 8 de marzo apenas prosperó en las siguientes jornadas, y a partir del 13 se produjo lentamente la retirada.

Un poco antes los rebeldes prepararon una nueva acción sobre Madrid. Esta vez se trataba de atacar por el Jarama mediante una doble pinza desde el noreste y el sureste para copar a las fuerzas enemigas. Cuando el día 24 de enero se produjo el ataque, las defensas republicanas se hallaban desguarecidas en varias zonas. Tanto los jefes de milicias comunistas Enrique Líster y Juan Modesto como el teniente coronel Vicente Rojo fueron avisados con antelación de las intenciones enemigas mediante informes previos $^{46}$. Los rebeldes habían comenzado a mover vehículos y tropas desde el 15 de enero y los servicios de información republicanos habían dado cuenta de ello47, aunque aún desconocían el momento y el lugar donde el enemigo asestaría el golpe.

En este caso, la información republicana se confundía de nuevo: pensaba que el ataque se daría más al Norte y creía que La Marañosa sería el punto más meridional por donde el enemigo rompería el frente. En realidad, La Marañosa iba a ser la zona más septentrional por la que operaría. Asimismo, el general Miaja no quería mover sus tropas de la capital para reforzar ese frente. Todo ello pilló desatendido el frente oriental de Madrid, de manera que los primeros días de contienda el enemigo avanzó casi sin problemas. Una vez que las unidades republicanas reforzaron las zonas a partir del día 16 de febrero, entonces se pasó al contraataque y se logró incluso detener al enemigo el 23.

Quince días más tarde, el enemigo lo intentaría de nuevo por Guadalajara. En esta ocasión el Corpo di Truppe Volontarie (CTV) tendría un papel destacado. Mientras, la información republicana no se enteraba del constante traslado y concentración de tropas enemigas en la zona de la Alcarria, sino que estaba más pendiente del peligro en el flanco occidental de Madrid «frente al Sector de las Rozas»48 y en general contra los flancos de la capital. Cuando se produjo el ataque hubo una mayúscula sorpresa aunque el Ejército de Centro no parecía darle importancia: «Quizás este ataque a la doce división sea para distraer fuerzas», llegó a escribirse en un programa de investigación ${ }^{49}$. El ataque iba en serio y el enemigo avanzó como pudo hasta Trijueque. A partir de ese

45 CDMH, Incorporados, 711, Cp. 1.

${ }^{6}$ GARCÍA RAMÍREZ, José Manuel, La batalla del Jarama, Madrid, Almena, 2007, p. 69; DÍEZ, Luis, La batalla del Jarama, Madrid, Oberon, 2005, p. 41.

47 AGMAV, A. 97, L. 971, C. 6-7, f. 30.

${ }^{48}$ AGMAV, A. 57, L. 614, C. 2, D. 1, ff. 2, 4, 5, 8, 10.

$49 \mathrm{CDMH}$, Incorporados, 711, Cp. 1. 
momento, los republicanos concentraron nuevas tropas, detuvieron la marcha de los italianos y lograron incluso hacer retroceder al enemigo, lo que se vendió propagandísticamente como la primera victoria del Ejército Popular en los campos de batalla.

Esta derrota colmó el vaso en el lado rebelde. Era la quinta vez que Franco intentaba tomar Madrid de manera indirecta y fracasaba. Sólo entonces entendió que quizá merecería la pena cambiar de estrategia y abundar en la conquista del frente norte.

\subsection{Información correcta pero enemigo poderoso (marzo-octubre 1937)}

Desde febrero los Servicios de Información del Gobierno Vasco y los del Cuerpo de Ejército de Euzkadi, habían comenzado a denunciar los propósitos del enemigo de atacar Vizcaya ${ }^{50}$. Sin embargo, el Ejército del Norte no había dado crédito a estas noticias ya que, en su opinión, las posibilidades enemigas eran «muy escasas» y la información militar de las fuentes nacionalistas «sumamente deficiente y arbitraria» 5 . Y es que el cuartel de Llano de la Encomienda, jefe del Ejército del Norte, negaba cualquier tipo de credibilidad a todo lo que procedía del entorno del Gobierno vasco.

Ya en marzo, un telegrama del cónsul de Bayona advirtió de nuevo sobre dicha posibilidad52. Pero el Ejército del Norte siguió quitándole hierro a las informaciones que anticipaban ya no sólo la inminencia del ataque enemigo sino incluso el punto de fractura, previsto en el frente de Elorrio-Elgueta, es decir, unos kilómetros más al norte de donde se produciría finalmente el asalto.

Los militares republicanos no podían creer que el enemigo fuera atacar con un número menor de efectivos y por un lugar, Ochandiano, considerado como uno de los mejor defendidos53. Pero así fue, y el 31 de marzo comenzó un ataque que llegaría a ser devastador porque la información había medido correctamente las fuerzas terrestres de los rebeldes y hasta el lugar de ataque, pero había descuidado el poder de su aviación, letal sobre ciudades como Guernica.

Durante el mes de abril el enemigo avanzó por Vizcaya y el 6 de mayo reanudó su ataque con el objetivo puesto en Bilbao. De las líneas de progresión diseñadas, la información republicana sólo tuvo constancia de la primera, aunque acertó señalando el peligro que se cernía sobre el Sollube y el Bizcargui. Del mismo modo, los servicios de

${ }^{50} \mathrm{CDMH}$, Incorporados, 715, Cp. 10 y AGMAV, A. 63, L. 854, C. 12, D. 4, f. 1.

${ }^{51}$ Síntesis General de Información en Ibidem.

${ }^{2}$ Telegrama de Modesto Arambarri a Llano de la Encomienda en Ibidem.

53 MARTÍNEZ BANDE, José Manuel, Vizcaya, Madrid, San Martín, 1971, p. 42. 
información del Ejército del Norte también determinaron el lugar por donde se rompería el Cinturón de Hierro: «en el frente Bizcargui-Fica»54. A pesar de ello, el 11 de junio las brigadas enemigas comenzaron las acciones previas de ruptura del frente por ese mismo lugar, que fue desbordado al día siguiente con una enorme masa artillera. Bilbao se tomó el 19 de junio.

La única manera de sostener el Norte era desviar la atención del enemigo atacando otro frente. En junio se decidió atacar Huesca, para lo cual se recurrió a los servicios de información. Estos determinaron que el objetivo debía ser esta ciudad aragonesa, debido a la debilidad de sus defensas 55 . Sin embargo, el enemigo conoció con antelación las maniobras de aproximación; y el ataque, eliminada la sorpresa, se estancó.

Fracasado este intento, se decidió llevar el impulso a la zona centro. Allí estaban las mejores tropas de la República y por ello se planeó una maniobra muy ambiciosa que pretendía embolsar al enemigo en la zona de Brunete-Navalcarnero-Cerro de los Ángeles. El despliegue de más de 80.000 soldados y cientos de carros de combate y piezas de artillería no podía prosperar sin la ayuda de la información, ya que había que elegir previamente el lugar por donde habría de romperse el frente. El espionaje republicano detectó la debilidad del enemigo en la zona donde se acantonaba parte de la $71^{\text {a }}$ división rebelde, cuyas fuerzas «eran escasísimas» y «la fortificación no alcanzaba la madurez y continuidad que en los frentes inmediatos a Madrid» 56 .

El 6 de julio se inició el ataque, en el que las tropas republicanas lograron un espectacular avance hasta Brunete, Quijorna y Villanueva. Allí se detuvieron para conquistar dichas plazas, lo que a la postre les costaría la victoria, ya que el enemigo aprovecharía ese parón para enviar nuevas tropas a la zona. Con este ataque el Ejército Popular había conseguido retrasar el avance en el teatro septentrional cinco semanas pero pagando un alto coste humano.

Franco siguió avanzando por el Norte. En junio, las noticias sobre propósitos de ataque en Cantabria comenzaron a ser recurrentes57. La información republicana era correcta y por ello se intensificaron los refuerzos y se construyeron obras de defensa en los puntos indicados. Un día antes del ataque, la información había contabilizado aparatos enemigos «en los aeródromos de Villarcayo y Gamonal, y concentraciones de italianos y marroquíes en Villarcayo, Barruelo y Aguilar de Campoo (Palencia)». Se esperaba un ataque con «fuertes masas artilleras y una numerosa potencia aérea» por

54 AGMAV, A. 63, L. 854, C. 14, D. 1.

55 AGMAV, A. 62, L. 771, C. 19; D.1, f. 22.

56 SALAS LARRAZÁBAL, Ramón, Historia del Ejército Popular de la República, Madrid, La Esfera de los Libros, 2006, p. 1713.

57 AGMAV, A. 63, L. 853, C. 16, D. 4, f. 2. 
la frontera con Burgos en la zona del Valle de Mena y la línea de Villasante, Bercedo y Noceco, y «muy próximos y fuertes ataques [...] hacia Mataporquera y Reinosa» 58 . Al día siguiente estos presagios se verían cumplidos casi punto por punto.

La información republicana había sido muy precisa y se reforzaron los sectores afectados59, pero la potencia enemiga resultó incontenible debido a su superioridad artillera, aérea y humana ${ }^{60}$. El avance enemigo se detuvo momentáneamente con la rendición de los soldados vascos en Santoña el 26 de agosto, lo que prácticamente significaba la pérdida de Cantabria.

Dos días antes, el Ejército del Este había iniciado una ofensiva contra Zaragoza con el fin de distraer al enemigo. Se trataba de un ataque contra la capital aragonesa llevado a cabo por cuatro agrupaciones de más de 100.000 hombres. El porqué de esta decisión se debió a las noticias que llegaban desde allí y que daban cuenta de una ciudad sometida por la violencia facciosa, y anhelante de su liberación por los republicanos.

Se trataba en realidad de una exageración basada en las noticias complacientes de evadidos. Aun así, varios guerrilleros y espías cruzaron las líneas durante el verano concluyendo que la plaza estaba guarnecida «con escasas fuerzas de no muy buena calidad. En Zaragoza, las reservas son escasas y mal instruidas» 61 .

Esta vez los republicanos sí lograron la sorpresa, pero ni siquiera en la primera jornada lograron alcanzar los objetivos marcados. Durante los días siguientes, el ataque se estancó en Belchite, repitiendo el error cometido un mes antes en Brunete.

El objetivo de distraer las fuerzas enemigas del Norte no se consiguió y el avance hacia Asturias siguió adelante. En este caso, los republicanos confiaban en que la difícil orografía y el clima adverso les serían de ayuda. Los servicios de información estaban alerta sobre el momento y el lugar del ataque. Agentes especiales se desvivieron durante el mes de septiembre, y dieron con los puntos de ruptura ${ }^{62}$. Sin embargo esta información no sirvió de mucho frente a la gran masa de hombres y máquinas de la que se acompañaba el enemigo. La resistencia duró apenas un mes, ya que el 21 de octubre se conquistaba Gijón, cerrando definitivamente la campaña del Norte.

\footnotetext{
58 Propósitos del enemigo en AGMAV, A. 63, L. 853, C. 9, D. 1, ff. 8-10. (13 de agosto de 1937) 59 AGMAV, A. 63, L. 853, C. 16, D. 3, 4

6o MARTÍNEZ BANDE, José Manuel, El final del frente Norte, Madrid, San Martín, 1972, pp. $54,56$.

${ }^{61}$ AGMAV, A. 62, L. 771, C. 19, D.1, f. 45.

62 AGMAV, A. 63, L. 857, C. 7, D. 1, f. 3.
} 


\subsection{Prever la derrota (octubre 1937-marzo 1939)}

A partir de ese momento la información se volvió vital. ¿Por dónde atacaría ahora el enemigo? El general Vicente Rojo, Jefe del Estado Mayor del Ejército Popular, dudaba entre dos lugares: Madrid o el teatro aragonés. La primera opción acabó descartándose, ya que la conquista sería «cruenta» y no creía que el enemigo quisiera «correr la aventura de un nuevo descalabro con el consiguiente desgaste y pérdida de tiempo». Por ello pensaba que la opción de atacar el teatro aragonés era la finalidad «militarmente más fácil y desde todos los puntos de vista la más útil»63. Es por ello que, entre otras razones, el Gobierno decidió abandonar Valencia y trasladarse a Barcelona.

Durante el último mes y medio los servicios de información republicanos habían advertido sobre dicha posibilidad ${ }^{64} \mathrm{y}$, acabada la campaña del Norte, la mayoría de la prensa internacional aseguraba que el siguiente movimiento de Franco sería cortar las comunicaciones entre Valencia y Barcelona ${ }^{65}$. El cónsul de Hendaya daba incluso una fecha, el 20 de noviembre, y se atrevía a calcular el volumen de maniobra de «200.000 hombres con gran masa artillería y 450 aviones ${ }^{66}$. Un agente infiltrado había afirmado que el próximo ataque sería antes de acabar el año, "probablemente por Teruel en dirección a la costa, entre Valencia y Barcelona»67.

La mayoría de informes daba por seguro la elección del teatro aragonés. Sin embargo, Franco, sobre quien recaía la última palabra a la hora de decidir el siguiente movimiento, emitió una orden el 28 de noviembre en la que se decidía a actuar sobre Madrid. Franco, siguiendo la lógica táctica que ya había empleado en la campaña del Norte: quería chocar primeramente contra el escollo más difícil para después avanzar más fácilmente.

Antes de que el enemigo actuase, Vicente Rojo decidió tomar la iniciativa y desempolvar el antiguo Plan Extremadura, rebautizado ahora como Plan $P^{68}$, mientras seguía pendiente de los movimientos enemigos. Aragón siguió siendo la mayor preocupación hasta mediados de noviembre, pero a finales de mes comenzó a temerse por Madrid debido a informaciones que recogían movimientos de vehículos en las

\footnotetext{
63 AGMAV, A. 54, L. 482, C. 2, D. 4.

$64 \mathrm{CDMH}$, Incorporados, 725, 5.8.3. Información del Cónsul de Hendaya en España

65 AGMAV, A. 62, L. 768, C. 12, D. 1, ff. 30, 31.

$66 \mathrm{CDMH}$, Incorporados, 725, 5.8.3. Información del Cónsul de Hendaya en España.

${ }_{7} \mathrm{CDMH}$, Incorporados, 720, Cp. 2.

68 CAMPANARIO, Juan Miguel, «Los proyectos fallidos del Ejército Popular de la República para dividir en dos la zona ocupada por el enemigo: El Plan P del general Vicente Rojo»,

URL: < http://www2.uah.es/jmc/planp.pdf > [consultado el 1 abril 2016].
} 
zonas defendidas por los Cuerpos II y IV ${ }^{69}$. A pesar de ello, en diciembre poco o nada se hizo por reforzar aquel frente, salvo posponer la ejecución sobre Extremadura y preparar otra ofensiva menos ambiciosa sobre otro lugar: Teruel.

La elección de esta ciudad vino nuevamente determinada por la acción del espionaje. Durante mucho tiempo éste había denunciado la escasez de tropas en torno a aquella plaza. Se contaban con todos los datos de hombres y armas del enemigo, disposición en el frente y la debilidad de la fortificación y la desorganización y deficiencia de las tropas. Si esta información no estaba equivocada - y no lo estaba nada podía evitar el éxito del ataque.

Y así fue. Con esta operación, que comenzó la madrugada del 15 de diciembre, la República conseguiría el 7 de enero tomar la ciudad. Pero el enemigo no estaba dispuesto a dejar así las cosas. La información republicana dio cuenta de la preparación ofensiva del enemigo y no descartaba un nuevo ataque ${ }^{70}$, algo que contrastaba con los deseos de algunos mandos republicanos que pretendían dar por zanjada la batalla ${ }^{71}$. Rojo quería pensar que Franco no intentaría recuperar Teruel, pero se equivocaba.

Los boletines de información reiteraban el peligro de un ataque próximo ${ }^{72}$, pero Rojo se empeñó en llevar a cabo el Plan $P$ y sacó de allí a sus tropas73. Lo que pasó a continuación fue un brutal ataque que se llevó por delante al Ejército de Levante y la reconquista de Teruel en apenas cinco días por parte del enemigo.

A partir de ese momento, aquél seguiría profundizando en su avance por Aragón con el fin de tomar Alcañiz (Teruel). En este frente, el enemigo contaba con un número similar de hombres, pero una superioridad artillera y aérea74. Entre el 9 y el 17 de marzo, los rebeldes avanzaron hasta la línea formada por Caspe-Alcañiz-CalandaAlcorisa. La información del Ejército del Este había avisado sobre movimientos de vehículos en aquellos sectores una semana antes del ataque, e incluso en los días siguientes se dio cuenta de la llegada de carros de combate y de actividad aérea75. La información había cumplido pero, a pesar de sus advertencias, no se había reforzado el frente suficientemente.

${ }^{69} \mathrm{CDMH}$, Incorporados, 684, Cp. 2; Incorporados, 674, Cp. 5; Incorporados, 675, Cp. 3, f. 93; Incorporados, 695, Cp. 8; Incorporados, 685, Cp. 1; AGMAV, A. 65, L. 987, C. 4, D. 1, f. 1, además de MERA, Cipriano, Guerra, exilio y cárcel de un anarcosindicalista, Paris, Ruedo Ibérico, 1976, pp. 160, 161.

${ }^{70} \mathrm{CDMH}$, Incorporados, 696, Cp. 1.

${ }^{71}$ AGMAV, A. 65, L. 786, C. 14.

${ }^{2}$ AHN, Archivo General Rojo, Caja 22/5.

73 LÍSTER, Enrique, Nuestra guerra, Paris, Ruedo Ibérico, 1963; CASTRO DELGADO, Enrique, Hombres made in Moscú, Barcelona, Luis de Caralt, 1963, p. 529.

74 SALAS LARRAZABAL, Ramón, op.cit., pp. 2273-2275.

75 AGMAV, A. 62, L. 769, C. 8; CDMH, Incorporados, 691, Cp. 1; Incorporados, 704, Cp. 5. 
$\mathrm{Al}$ poco de sufrir este revés, la información republicana se enfrentaba a una nueva disyuntiva: ¿proseguiría el enemigo su ofensiva hacia el Mediterráneo o preferiría un «ataque contra Madrid por frente Guadalajara y quizá Jarama una vez encontrada fuerte resistencia propia en frente Este»?76.

Se habían visto numerosas divisiones enemigas desplegadas en la zona y parecía que podría explotarse el éxito hasta la línea Gandesa-Tortosa, pero también había movimientos sospechosos y muchos informes de informes de evadidos y agentes que apuntaban hacia Madrid. De hecho, Rojo se debatía entre ambas posibilidades, aunque parecía deseoso de llevar «las reservas a Madrid». Tanto que obvió o no llegó a enterarse de unas informaciones que daban «como más probable» la primera hipótesis, es decir, que el mando enemigo había decidido «proseguir la ofensiva con el propósito de llegar hasta la costa mediterránea»77.

Vicente Rojo había desestimado nuevamente una valiosísima información ${ }^{78}$ y el resultado fue una nueva derrota. El 14 de marzo se inició un ataque con el que el enemigo llegó a controlar casi 7.000 kilómetros cuadrados. En la purga de responsabilidades la información quedó absuelta de toda culpa.

Sin apenas respiro, los rebeldes siguieron marchando hacia el mar siguiendo dos rutas: una principal por el sur del Ebro y otra secundaria al norte del río. La información está vez entendió que el enemigo desplegaría toda su fuerza sólo por el sur79. A pesar de que concentraron sus esfuerzos en dicha margen nada pudieron hacer contra el ímpetu y la superioridad militar de los rebeldes, que alcanzaron la costa el 15 de abril en Vinaroz (Castellón).

Por otro lado, la ofensiva auxiliar por el norte del Ebro, iniciada el 22 de marzo, fructificó más de lo previsto inicialmente debido a que desde el bando republicano se pensó que el avance por el sur era el decisivo ${ }^{80}$. Tiempo atrás se había anunciado el trasiego de tropas y vehículos enemigos por dicho sector y las sospechas fueron creciendo hasta los días previos al ataque, llegándose a "clavar" el sitio por donde se llevaría finalmente a cabo ${ }^{81}$. Sin embargo, y nuevamente no se le prestó el interés debido y el enemigo llegó hasta Lérida. Esto conllevó la dimisión de Indalecio Prieto como Ministro de Defensa y a la práctica desaparición del Ejército del Este.

\footnotetext{
${ }^{6} \mathrm{CDMH}$, Incorporados, 704, Cp. 5

$77 \mathrm{CDMH}$, Incorporados, 704, Cp. 5.

78 ENCINAS MORAL, Ángel L. (ed.), Las causas de la derrota de la República de España. Informe elaborado por Stoyán Mínev (Stepanov), Madrid, Miraguano, 2003, p. 109.

$79 \mathrm{CDMH}$, Incorporados, 704, Cp. 6.

80 AGMAV, A. 54, L. 507, C. 8, D. 2 f. 107.

81 AGMAV, A. 62, L. 769, C. 9; CDMH, Incorporados, 711, Cp. 3; Incorporados, 704, Cp. 5.
} 
Todas las apuestas apuntaban a que el siguiente movimiento enemigo sería contra Cataluña, pero inexplicablemente no fue así. En una fecha tan remota como octubre de 1936 un espía republicano había revelado el plan estratégico del enemigo: tras la toma de Madrid, «el grueso del ejército pasaría a liquidar el asunto del Cantábrico» para después regresar «nuevamente a la llanura del Tajo. Iniciaría inmediatamente, y por la llanura, la marcha sobre Valencia», llevando a cabo acciones secundarias «sobre los Pirineos» a fin de destruir «las comunicaciones ferroviarias con Francia» e «imposibilitar los movimientos de tropas y el abastecimiento del extranjero». Sólo «si la caída de Valencia llegara a ser un hecho [...] se iniciaría la destrucción de Catalunya» ${ }^{82}$.

En Madrid se había fracasado pero por lo demás el plan se había cumplido. Valencia parecía el objetivo próximo y, de nuevo, la información acertó. El 10 de abril de 1938 se aseguraba que lo «más probable» era que el enemigo continuara su campaña «progresando por la llanura levantina para alcanzar Sagunto y Valencia y envolver todo el frente del Ejército de Levante» ${ }^{83}$.

A pesar de ello, los ataques continuaron por la provincia de Teruel y por la costa hacia Castellón, entre abril y junio, lográndose un desgaste mutuo. Los boletines de información anticipaban acertadamente las intenciones de su enemigo ${ }^{84}$ y gracias a ello se fortificaron algunas localidades y se enviaron nuevos refuerzos.

En la batalla de Levante se estaba conteniendo eficazmente al enemigo, pero Vicente Rojo tenía otros planes. Se trataba de atacar en un frente alejado para desviar la atención del enemigo sobre Valencia. En concreto se había planeado cruzar el Ebro y alcanzar la línea Fayón-Batea-Valderrobles-Beceite y la margen izquierda de los ríos Mangrané y Serbol con las mejores tropas del Ejército Popular, que contaban con casi 100.000 efectivos.

Para llevar a cabo este ataque, los servicios de información hubieron de realizar una titánica labor para elegir los puntos más favorables para el franqueo del río. Desertores, observadores agudos, infiltrados o exploradores tenían por misión «cruzar el río dos veces, en cada raid, nadando 150-200 metros cada vez. En su propia orilla debían echarse al río sin ruido para cruzarlo y salir a la opuesta con el mayor sigilo, sin dejar el menor rastro de su paso» ${ }^{85}$. Además se ordenaron varios programas de investigación,

\footnotetext{
82 AGMAV, C. 227, Cp. 1, D. 2 / 46-47.

83 AGMAV, A. 54, L. 507, C. 1, D. 3, f. 59.

84 AGMAV, A. 64, L. 777, C. 15, ff. 4, 8, 13, 23y CDMH, Incorporados, 699, Cp. 1.

85 LÍSTER, Enrique, op.cit., p. 202; TAGÜEÑA, Manuel, Testimonio de dos guerras, Barcelona, Planeta, 2005, p. 202; MODESTO, Juan, Soy del Quinto Regimiento, Barcelona, Laia, 1978, p. 176.
} 
en uno de los cuales, el $\mathrm{n}^{\circ} 6$, correspondiente al 15 de mayo, se consignaron la mayor parte de los datos necesarios para la ofensiva de julio ${ }^{86}$.

Gracias a ello se cruzó el río finalmente en la medianoche del 25 de julio. Punto por punto se fueron cumpliendo las indicaciones que los servicios de información habían sugerido. Sin embargo, a pesar del exitoso cruce, el avance se detuvo en Villalba de los Arcos y Gandesa, ya que el enemigo se había reforzado y había neutralizado el ataque con bombas sobre puentes y pasarelas. Allí se estancó la situación hasta el 16 de noviembre, cuando las tropas republicanas cruzaron de nuevo hacia la margen izquierda del río. Hasta entonces se produjo la batalla más larga de la Guerra Civil con un coste aproximado de 30.000 bajas.

Mientras esto ocurría, en julio se llevó a cabo el cierre de la bolsa de la Serena o de Mérida. El ataque de los rebeldes no cogió desprevenido al Ejército Popular, que conoció las intenciones del enemigo gracias a evadidos y agentes del SIEP87, aunque las tropas republicanas fueron desbordadas al inicio. El porqué de este fracaso se debe a que se habían trasladado fuerzas y material de Extremadura para ayudar en la defensa del Frente de Levante pues «una pulgada de terreno en Levante tenía el mismo valor que el de mucho kilómetros en Extremadura»88, quedando en la zona pocos y malos medios. El cierre de la Bolsa de la Serena supuso la conquista de $3.500 \mathrm{~km}^{2}$ en tan sólo cinco días de lucha y después la estabilización del frente.

Una vez acabó la batalla del Ebro, Franco reorganizó rápidamente sus tropas y «barajó la posibilidad de volverse contra el Centro-Sur y reanudar las batallas de Madrid o Valencia» ${ }^{89}$, aunque finalmente se decantó por un ataque contra Cataluña.

El Ejército Popular se desplegaba desde los Pirineos hasta el Ebro, con gran carencia de medios, especialmente en artillería y aviación. Mientras, los servicios de información reconocían que el enemigo tendría mayores probabilidades de éxito si actuaba en Cataluña por varias razones: evitaría el traslado de fuerzas, podría actuar sobre la retaguardia republicana desde Mallorca, y a pesar de que los republicanos tenían concentrados en Cataluña sus efectivos aéreos, esto producía en realidad un aumento de «las dificultades para nuestro despliegue y de la vulnerabilidad de nuestras bases»90. La información republicana preveía la utilización sistemática del cielo por parte del enemigo con más de un mes de antelación y no se equivocó en el pronóstico:

\footnotetext{
86 CDMH, Incorporados, 711, Cp. 3.

87 AGMAV, A. 62, L. 775, C. 10, p. 3; A. 54, L. 473, C. 4, D. 2, f. 29; AGMAV, A. 62, L. 773, C. 6. 88 AGMAV, A. 54, L. 473, C. 6.

89 CARDONA, Gabriel, Historia militar de una guerra civil, Barcelona, Flor del Viento, 2006, p. 318.

$90 \mathrm{CDMH}$, Incorporados, 705, Cp. 3
} 
la aviación franquista castigaría duramente con fuertes y continuados bombardeos no sólo las posiciones de vanguardia y a las tropas republicanas, sino también su retaguardia y a la población civil91.

Se esperaban dos acciones combinadas: un ataque contra el sector del Bajo Segre, donde realizaría su esfuerzo principal «dándose por descontada la dirección de ataque Asentiu-Artesa de Segre», y otra maniobra secundaria por el sector de Tremp92. La fecha era más difícil de determinar pero el Ejército Popular estaba listo para batirse en lo que se presumía iba a ser su último gran duelo.

Mientras, Vicente Rojo decidió distraer al enemigo con un ataque triple en la región central: contra Motril, contra la línea Córdoba-Peñarroya, y contra las comunicaciones entre Madrid y Extremadura. Los dos primeros se llevaron a cabo y en ambos la información jugó un papel destacado señalando las grietas en el puerto93, y las debilidades enemigas en el otro punto94. Razones de diversa índole evitaron que dichos ataques fructificasen: en el primero el general Miaja decidió no participar y en el segundo, el avance fue detenido por el enemigo y por «la pobreza de medios y la falta de iniciativa y de técnica de los jefes de algunas grandes unidades»95.

Como estos intentos de diversión no tuvieron éxito, el final de la guerra se dirimiría en Cataluña. Finalmente, el 23 de diciembre se produjo el ataque largamente anunciado. La información republicana aguardaba un ataque más potente ${ }^{96}$, pero aun así las fuerzas leales y sus reservas se vieron desbordadas por la artillería enemiga. El avance fue imparable y los pueblos y ciudades catalanas fueron cayendo mientras soldados y civiles huían hacia la frontera francesa. La guerra había terminado.

\section{Conclusiones}

Los servicios de información del Ejército Popular pasaron de ser unos meros "buzones" o "cajones de sastre" donde se almacenaba los informes que llegaban de manera confusa a Madrid desde cualquier punto de la Península a convertirse en una organización centralizada y apta para captar los mensajes del enemigo que delataran sus capacidades e intenciones.

${ }^{91}$ SOLÉ I SABATÉ, Josep, VILLARROYA, Joan, España en llamas. La guerra civil desde el aire, Madrid, Temas de hoy, 2003, pp. 232-246.

${ }^{2} \mathrm{CDMH}$, Incorporados, 705, Cps. 3, 4.

$93 \mathrm{CDMH}$, Incorporados, 721, Cp. 7.

94 AGMAV, A. 62, L. 774, C. 1, D. 1, ff. 108, 112.

95 ROJO, Vicente, iAlerta los pueblos! Estudio político-militar del período final de la guerra española, Esplugues de Llobregat, Ariel, 1974, p. 110.

${ }_{96} \mathrm{CDMH}$, Incorporados, 705, Cp. 4. 
El proceso de creación y evolución del estos servicios fue similar al del Ejército Popular en tanto que todo el personal tuvo que adaptarse a procedimientos y formas a los que no estaba acostumbrado. Esta transformación, realizada durante la guerra y bajo condiciones muy difíciles, fue promovida desde el comienzo por Manuel Estrada Manchón. Sin él, es posible que dicha estructura jamás hubiera alcanzado los niveles de organización que finalmente logró. Y ello a pesar de las reticencias con las que tanto Indalecio Prieto como Vicente Rojo recibieron los proyectos para convertir la Segunda Sección del Estado Mayor del Ejército de Tierra en el Servicio de Inteligencia Militar del Ministerio de Defensa.

Se crearon nuevas secciones o negociados especializados con los que obtener y tratar mejor la información. Su desarrollo en apenas un año fue extraordinario, teniendo en cuenta el tiempo que se tarda en crear este tipo de servicios, aunque sus resultados no pudieron alcanzar un éxito rotundo y su eficacia fue dispar.

Desde el punto de vista ofensivo, la información fue, en general bastante buena, pues sirvió para señalar los lugares donde el enemigo se encontraba más desguarecido. En algunas ocasiones, como en Huesca, el enemigo se reforzó a tiempo, pero en la mayoría de las operaciones (Brunete, Belchite, Teruel, el Ebro y Peñarroya) el Ejército Popular rompió por aquellos puntos débiles y sorprendió a su enemigo. Sin embargo, en todas esas batallas, salvo Teruel, el resultado fue negativo, pues no se lograron los objetivos previstos. No falló la información sino otros factores como la falta de preparación o la disciplina de los soldados, que no supieron aprovechar la sorpresa y hasta su superioridad material al inicio.

Por lo que se refiere a la información defensiva puede sacarse la siguiente conclusión: en las primeras batallas del frente central (Madrid, los tres choques en la carretera de La Coruña, Jarama, y en Guadalajara) los servicios de información nunca previeron el ataque enemigo y, sin embargo, el resultado no fue del todo malo, ya que, a pesar de las numerosas bajas, al menos se logró frustrar el objetivo de tomar Madrid. En este caso, la debilidad del enemigo, la rápida capacidad de reacción propia y hasta un poco de suerte, inclinaron la balanza favorablemente.

Paradójicamente, salvo en las batallas de Pozoblanco y la campaña de Levante, en las batallas que siguieron, el Ejército Popular gozó de una buena información sobre el enemigo, pero el resultado fue la derrota. En algunos casos, como Santander, Asturias y Cataluña, la superioridad enemiga era tan aplastante que poco o nada se podía hacer, a pesar de la información. En otros casos, los refuerzos humanos y materiales que se pidieron o que se necesitaban no llegaron a tiempo, a pesar de que se denunciaron con antelación los movimientos del enemigo. En casos como Málaga o el cierre de la bolsa 
de Mérida, la situación en otros frentes (Jarama y Ebro) escatimó el refuerzo en el otro lado. En otras ocasiones, los erróneos criterios de Vicente Rojo en Teruel y Aragón, que siguió empecinado en sacar a las tropas de allí para llevarlas a Extremadura, le hicieron descuidar la información que le advertían del peligro sobre aquellas zonas. En Vizcaya, donde los servicios de información vascos alertaron del ataque, las desavenencias personales entre Llano de la Encomienda y el lehendakari Aguirre sirvieron para obviar las informaciones que alertaban del peligro que se cernía sobre la zona.

En definitiva, la información con la que contó el Ejército Popular fue mejorando sustancialmente al tiempo que, de manera paradójica, decrecía su capacidad militar. Todo ello parece confirmar que los servicios de información no fueron responsables de la derrota, entre otras cosas porque su trabajo no fue tan decisivo, como por otra parte ocurrió igualmente en otros conflictos contemporáneos como la Segunda Guerra Mundial97.

97 A este respecto acaba de publicarse recientemente HASTINGS, Max, La guerra secreta. Espías, códigos y guerrillas, 1939-1945, Barcelona, Crítica, 2016. 


\section{* El autor}

Hernán Rodríguez Velasco es Doctor en Historia por la Universidad de Salamanca (2007) y Master en “War Studies” en el War Studies Department del King's College London (2008). Se ha especializado en Historia Militar y en los Servicios de Información y espionaje durante la Guerra Civil Española. Es autor de varios artículos y capítulos de libros relacionados con dichos temas en revistas como «Ayer» o «Studia Historica», «Historia Contemporánea», así como de una biografía del coronel Manuel Estrada Manchón en la obra conjunta 25 Militares de la República (Madrid, Ministerio de Defensa, 2011), y de un libro titulado Una derrota prevista. El espionaje republicano en la Guerra Civil española (1936-1939) (Granada, Comares, 2012). Es colaborador de la revista «Desperta Ferro» y socio fundador de la Asociación Española de Historiadores Militares (ASEHISMI).

URL: < http://www.studistorici.com/progett/autori/\#RodriguezVelasco >

\section{Per citare questo articolo:}

RODRÍGUEZ VELASCO, Hernán, «El espionaje militar republicano durante la Guerra Civil Española», Diacronie. Studi di Storia Contemporanea : La voce del silenzio: intelligence, spionaggio e conflitto nel XX secolo, 29/12/2016, URL:< http://www.studistorici.com/2016/12/29/rodriguez-velasco_numero_28/ >

Diacronie Studi di Storia Contemporanea 0 www.diacronie.it

Risorsa digitale indipendente a carattere storiografico. Uscita trimestrale. redazione.diacronie@hotmail.it

Comitato di redazione: Jacopo Bassi - Luca Bufarale - Antonio César Moreno Cantano - Deborah Paci - Fausto Pietrancosta - Alessandro Salvador - Matteo Tomasoni - Luca Zuccolo

Diritti: gli articoli di Diacronie. Studi di Storia Contemporanea sono pubblicati sotto licenza Creative Commons 3.0. Possono essere riprodotti e modificati a patto di indicare eventuali modifiche dei contenuti, di riconoscere la paternità dell'opera e di condividerla allo stesso modo. La citazione di estratti è comunque sempre autorizzata, nei limiti previsti dalla legge. 